\title{
CONSTRUÇÃO DOS MAPAS-MÚNDI NOS SÉCULOS XV E XVI: ENTRE A TRADIÇÃO E A EXPERIÊNCIA
}

Lucas Montalvão Rabelo Orientação: Andréa Doré

PALAVRAS-CAHVE: Renascimento; história da cartografia; grandes navegações.

Os mapas são objetos que desde sempre exercem uma fascinação sobre o homem dada a sua capacidade de dispor o mundo diante dos olhos. Essa pesquisa teve como meta desvendar um pouco desse olhar voltando-se para um importante período da história Ocidental, o Renascimento. Acompanhou-se, assim, o processo de produção de mapas ao longo da segunda metade do século XV e o século XVI.

Esses mapas-múndi estavam inseridos em uma época importante de efervescência dos debates acerca da geografia terrestre suscitados pelas relações entre o ideal de mundo medieval, o conhecimento recente dos autores clássicos que havia muito estavam perdidos e as descobertas realizadas durante as viagens empreendidas pelos ibéricos. Foi um período que representou um momento de síntese não somente na história da cartografia, mas em muitos outros campos da história. Esse embate pode ser sintetizado na afirmação de Maria Fernanda Alegria:

A cartografia oferece-nos um excelente exemplo para ilustrar [o] complexo confronto entre o que os livros e a tradição oral registram, entre o que os mestres ensinam e o que se aprende com a própria experiência. Na luta entre esta dupla linha de forças [tradição e experiência], a persistência do vivido 
pelos Portugueses teve um papel fundamental na alteração das mentalidades. ${ }^{1}$

Essa alteração de mentalidade refere-se à experiência dos portugueses ao longo das grandes navegações. Pois, de acordo com João de Castro Osório foi através da aprendizagem cotidiana dos novos espaços que a realidade do mundo se apresentava outra, diferente de tudo aquilo que os eruditos europeus diziam, ou os autores clássicos. Assim, todo o pensamento anterior foi sendo posto em confronto com a realidade, sem que tivesse de ser desde logo abandonado pelas verdades nascidas da experiência vivida e dos ensinamentos da realidade vista e observada. ${ }^{2}$ Essa mudança pode, então, ser verificada nos mapas renascentistas.

Aos poucos eles deixam de ser predominantemente simbólicos e passam a privilegiar uma representação geográfica, o que é enriquecido pelas informações provindas das viagens portuguesas. No entanto, essas mudanças não ocorrem de forma progressiva, mas sim lentamente e por vezes acontecendo retrocessos. As representações do mundo seguindo o ideal medieval, como o exemplo dos mapas tipo T$\mathrm{O}^{3}$, em que a concepção de mundo é estritamente ligada ao modelo bíblico, vai sendo suplantada pelas características ditas modernas, em que há a preocupação com a correspondência ao “real”. Esse percurso

\footnotetext{
${ }^{1}$ ALEGRIA, Maria Fernanda, et alli. Cartografia e Viagens. In: BETHENCOURT, F. \& CLAUDHURI, K(dir.). História da Expansão Portuguesa. Vol I. Lisboa: Circulo de Leitores, 1998, p. 26.

2 Ver OSÓRIO, João de Castro (org.). Idearium Antologia do Pensamento Português: A Revolução da Experiência. Lisboa: SNI, 1947, p. 16.

${ }^{3}$ Para mais informações sobre os mapas em estilo T-O, ver THROWER, Norman J.W. Maps \& Civilization: cartography in culture and society. Chicago: The University of Chicago Press,1996, p. 42; RANDLES, W. G. L. Da Terra Plana ao Globo Terrestre: uma rápida mutação epistemológica 1480-1520. Lisboa: Gradiva, 1980, pp. 15-16; MARQUES, Alfredo Pinheiro. A Cartografia dos Descobrimentos Portugueses. Lisboa: Elo, s/d.; CRONE, G. R. Historia de los mapas. México Buenos Aires: Fondo de Cultura Econômica, 1956; KIMBLE, G. H.T. A Geografia na Idade Media. Londrina: Eduel, São Paulo: Imprensa oficial do Estado de São Paulo, 2005.
} 
cartográfico ocorre desde o final da Idade Média, onde os relatos sobre viagens longínquas, até os confins da Ásia, como do veneziano Marco Polo, proporcionam à Europa Ocidental os primeiros dados mais seguros sobre áreas praticamente desconhecidas. Entretanto, essas informações confundiam-se com fábulas que misturavam essas experiências com outras provindas da Bíblia ou da literatura clássica. No período soma-se ainda o resgate das idéias de autores clássicos provindas de fontes árabes ou bizantinas. Um importante caso é de Ptolomeu, que é amplamente utilizado como base para construção de inúmeros mapas-múndi no século XV. Sua autoridade muitas vezes entrou em conflito com as novidades trazidas pelos relatos das viagens portuguesas, e, em muitos casos, suas informações se sobrepujaram às provindas das viagens marítimas, levando ao descrédito o conhecimento dos portugueses. ${ }^{4}$

Nesse período os cartógrafos eram solicitados a criar um determinado mapa-múndi para um monarca, ou quem o pudesse custear. A produção destes objetos tinha um alto custo econômico, o que criava uma relação de dependência do cartógrafo, pois ele deveria criar um mapa segundo as exigências daquele que o contratou. No entanto, mesmo que estivesse criando para seu patrocinador, o seu produto final apresenta uma série de elementos particulares, assim como, da sociedade na qual ele estava inserido. Ou seja, seu produto final estava intimamente ligado com as questões envolvendo o seu contexto próprio. Mesmo no interior de um movimento de valorização da experiência na produção dos mapas-múndi, deve ser observada também essa particularidade referente ao cartógrafo. Dependendo dos objetivos propostos para um determinado mapa ele poderia se valer tanto mais da experiência do "real" como das informações da "tradição”.

As fontes para essa pesquisa foram seis mapas produzidos ao longo dos séculos XV e XVI. São obras pertencentes a um período de cem anos iniciando no mapa de Fra Mauro (1459) indo até o

${ }^{4}$ GOMES, Maria do Carmo Andrade. Velhos Mapas, novas leituras: revisitando a historia da cartografia. São Paulo: GEOUSP, 2004. 
Planisfério de André Homem (1559). Esses mapas-múndi selecionados estão entre os que sobreviveram, e de alguma maneira são marcantes na história da cartografia renascentista. Busca-se apontá-los e mostrar de forma breve porque são considerados grandes marcos:

- Fra Mauro (1459): Mostra o início das explorações portuguesas na costa da África além de incluir os relatos de viajantes como Marco Polo nas representações geográficas;

- Henricus Martellus (1489): É considerado um dos primeiros mapas renascentistas. Um marco por ter iniciado a inclusão das descobertas portuguesas e de viajantes como Marco Polo mais a fundo do que Fra Mauro;

- Juan de La Cosa (1500): É o primeiro registro cartográfico do Novo Mundo sendo resultado direto da descoberta empreendida por Cristóvão Colombo;

- Cantino (1502): Uma referência na cartografia ao se tratar de Grandes Navegações, mostra um continente americano definido mais claramente que no mapa de Juan de La Cosa. O contorno do continente africano é mais próximo ao real nas proporções norte/sul. Por isso, este mapa é considerado o primeiro registro cartográfico "moderno".

- Diogo Ribeiro (1529): É considerado uma das melhores produções cartográficas deste período. Ele inova por colocar os resultados das expedições de Colombo, Caboto, dos irmãos Corte Real, Fernão de Magalhães, entre outros;

- André Homem (1559): O planisfério de André Homem mostra um avanço com relação ao contorno dos continentes. Nele já aparecem representações mais fiéis da América, África e Ásia.

A partir desta obra os grandes traços da geografia do planeta estavam construídos.

A grande questão buscada a partir desses mapas foi analisar como eles dispunham as informações do ofício cartográfico provenientes de duas fontes: dos modelos legados pelo período medieval e pelos autores clássicos, representando a tradição erudita; e 
as cartas-portulano e mapas produzidos diretamente das grandes navegações, inserindo a experiência. Dessa forma, como o cartógrafo ao produzir seu mapa incluía essas informações? Existia a predominância de uma, ou uma combinação entre elas? E como ela se realizava?

Para responder a essa questão foi utilizada uma metodologia de estudo fundamentada nas propostas de análise cartográficas empreendidas por J. Brian Harley. Grande crítico das abordagens tradicionais, afirma que ao se estudar os mapas deve-se estar atento ao contexto político próprio para compreender como o poder opera através do discurso cartográfico, e os efeitos desse poder na sociedade. Sua proposta é estudar os mapas mais como textos do que como imagens da natureza. Pois os mapas representam uma linguagem gráfica, uma construção feita a partir da realidade carregada de intenções e conseqüências que podem ser estudadas nas sociedades da época da produção de um determinado mapa. Igualmente aos livros, eles também são produtos de mentes individuais assim como de valores culturais mais amplos de sociedades específicas. ${ }^{5}$

Com isso, essa pesquisa visou um enfoque voltado não apenas às questões técnicas, mas também aos elementos que revelam o contexto social próprio da época em que este mapa encontra-se inserido, observando-o como um espelho da sociedade que o produziu dentro do embate renascentista. É, portanto, sobre essa nova ótica acerca da história da cartografia que essa pesquisa se orienta.

No primeiro capítulo desta monografia faz-se uma descrição do contexto das produções cartográficas acessíveis aos cartógrafos renascentistas. Elas foram subdivididas em duas partes. A primeira remete aos mapas-múndi produzidos na Baixa Idade Média, tanto esquemáticos, como os já mencionados T-O, quanto descritivos. Depois, no século XV incluiu-se a influência de Cláudio Ptolomeu, considerado o maior astrônomo da Antiguidade, que deixou vários

${ }^{5}$ HARLEY, J. B. La Nueva Naturaleza de los mapas. México: Foundo de Cultura Econômica, 2005, p. 60 e 61. 
escritos, entre eles sua Geographia. Essa obra retornou ao Ocidente no século $X V$ e trouxe uma renovação das representações cartográficas ganhando o status de autoridade no período. Esse primeiro grupo pertence a uma tradição erudita de uma cartografia essencialmente terrestre o que constituiu uma barreira às inovações de ordem prática.

A segunda subdivisão refere-se primeiramente às produções das cartas-portulano, iniciadas no século XIII, provenientes das experiências no mar Mediterrâneo. Em seguida inclui as navegações portuguesas iniciadas após a conquista de Ceuta em 1415. Com elas foi produzido todo um conjunto de mapas das costas africanas utilizados para fins náuticos. Infelizmente esses exemplares cartográficos não sobreviveram devido ao seu desgaste, mas os relatos sobre eles aparecem nas fontes da época. Como é o caso das notas no mapa de Fra Mauro. Toda essa nova produção cartográfica trouxe um conhecimento sobre o continente africano, em um primeiro momento, e a América posteriormente, influenciando decisivamente as novas produções cartográficas a partir da segunda metade do século XV. Desta forma, as cartas-portulano mediterrânicas e atlânticas nasceram da experiência marítima fruto de fins fundamentalmente práticos.

Em um segundo capítulo procurou-se descrever o contexto do autor e da sociedade. Aqui se estabeleceram as especificidades relacionadas com o autor, diferentemente do legado provindo de outros mapas. Foram investigadas as possíveis influências dentro da arte de cartografar desses indivíduos. Isso incluiu os responsáveis por encomendar a obra e, portanto, as suas expectativas para com o produto final, as disponibilidades técnicas para tal produção, como o caso dos mapas manuscritos e a imprensa, que marcou uma mudança profunda na divulgação dos mapas-múndi principalmente no século XVI.

Em relação a André Homem, ele pertencia às chamadas "escolas" cartográficas. Elas se constituíam em oficinas com uma tradição estilística própria. Em muitos casos contavam com 
familiares, tendo suas raízes nos ambientes da cartografia mediterrânica. No século XVI havia verdadeiras "dinastias" de cartógrafos, como a da família Reinel, a da família dos Homens e da família Teixeira. Porém, estar ligado a essas escolas não significava viver sempre no mesmo local. Muitos cartógrafos portugueses exerceram essa atividade no exterior atraídos por vantajosos contratos, quer temporariamente, como é o caso de Jorge de Reinel, que esteve um período em Sevilha; ou no decurso de sua vida ativa como Diogo Ribeiro, que só trabalhou em Sevilha, ou como Diogo Homem, que esteve em Londres e depois fixou-se definitivamente em Veneza. No caso de André Homem, ele era filho de Lopo Homem e irmão de Diogo Homem e foi o cosmógrafo do Rei de França. Realizou sua obra em Antuérpia, o que causou grande impacto em sua época sendo considerado por Richard Haklut o "príncipe dos

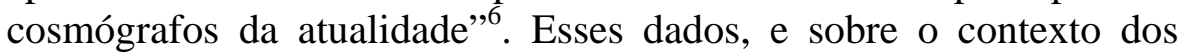
outros cartógrafos foram analisados na forma como influenciaram a produção do mapa

Na segunda parte dessa etapa, diante de todas as informações apontadas, buscou-se observá-las dentro do dilema do homem da época referente ao confronto surgido entre a tradição e a experiência. Para exemplificar essa questão, além dos mapas-múndi foram utilizadas algumas fontes escritas do período, como o Esmeraldo de Situ Orbis de Duarte Pacheco Pereira ${ }^{7}$, para mostrar como esse embate estava presente na sociedade.

Além de Harley e seu método, a autora Marica Milanese foi de grande importância. Ela defende a idéia de que os mapas produzidos ao longo dos séculos XIV e XV, na época dos descobrimentos geográficos, se enquadram em um processo de "síntese cartográfica". Ela contraria a noção tradicional dos cartógrafos positivistas que

${ }^{6}$ Para mais detalhes sobre as escolas cartográficas, ver MARQUES, op. cit., pp. 4964; ALBUQUERQUE, Luís (dir.). Dicionário de História dos Descobrimentos Portugueses. v. I. Lisboa: Caminho, 1994, p.216.

${ }^{7}$ PEREIRA, Duarte Pacheco. Esmeraldo De Situ Orbis, Lisboa: Fundação Calouste Goulbenkian, 1991. 
acreditam numa idéia de “transição cartográfica”. De acordo com a autora, os mapas deste período confluem experiências culturais e técnicas diversas, não se podendo falar em transição porque isso sugeriria um fluxo unidirecional que não existe na história da cartografia. $^{8}$

$\mathrm{O}$ estudo dos mapas pertencentes aos séculos XV e XVI contribuiu para a elucidação de um período importante da história ocidental. Os mapas são representações gráficas de todo um conjunto de pensamento e crenças de uma determinada época. Analisar essa série cartográfica do século XV e XVI foi uma forma de acompanhar essas mudanças ou permanências no pensamento; compreendendo que dentro de um mesmo período podem existir olhares diversos. Assim, com esse estudo analisou-se como o peso dos autores clássicos e o saber medieval relacionavam-se com as novas fontes de informações geográficas: as descobertas ibéricas.

Desta forma, ao fim da pesquisa, concluiu-se que os mapas renascentistas não se filiam apenas a informações provindas ou da tradição ou da experiência. Pelo contrário, elas se combinam, mesmo com o prosseguimento das explorações ibéricas pelo mundo. A experiência náutica contribuiu para a construção do contorno exato das regiões com conhecimento anterior apenas erudito, mas, ainda existem as regiões onde a tradição predomina. Como o caso do interior do continente africano, onde ocorre a permanência de um local mítico para a nascente do rio Nilo, o Monte da Lua.

Isso pode ser exemplificado com a contradição presente na obra de Fra Mauro. Dentro de todo esse esforço para realizar sua obra, o veneziano se coloca diante do problema da veracidade de suas informações. Para que seu testemunho através desse objeto visual seja legitimado, o cartógrafo indica que ele foi feito, através das informações da experiência de outros indivíduos contemporâneos que relatam fatos vistos com seus próprios olhos. Essa convicção encontra-se em uma das inscrições presentes em seu mapa:

${ }^{8}$ MILANESE, Marica apud ALEGRIA, Maria Fernanda, et alli. Op. cit., p. 31. 
Em meu tempo me é esforçado por comprovar os escritos com a experiência, ao largo de muitos anos de investigação e trato com pessoas dignas de maior crédito, as que tem visto com seus próprios olhos a verdade de quanto digo. ${ }^{9}$

Essa estratégia de legitimação é uma retomada de uma tradição provinda de Heródoto, pois ele foi o primeiro a considerar a importância da viagem, da verificação, para a compreensão do mundo, distinguindo a fábula da verdade. ${ }^{10}$

Assim, essa busca por mostrar apenas aquilo que provém de “cousa vista" - entendida enquanto informação do "real” obtida com a experiência - esbarra na força da tradição, presente ainda na forma de lendas ou mitos. Isso pode ser comprovado pela legenda colocada no extremo meridional de seu mapa onde se lê:

Até o ano de nosso Senhor de 1420 um barco da Índia, em uma travessia do mar da Índia até as ilhas dos homens e das mulheres, foi levado mais para lá do cabo de Diab através das Ilhas Verdes e a obscuridade até o oeste e o sudoeste por quarenta dias, não encontrando outra coisa que ar e água; segundo seus cálculos se percorreram 2.000 milhas e a sorte os abandonou. Regressaram ao dito Cabo de Diab em setenta dias e, ao parar próximo a costa para aprovisionar-se, os navegantes viram um ovo de um pássaro chamado roc, sendo o ovo tão grande como um tonel de sete galões e o tamanho do pássaro é tal que desde a ponta de uma asa a outra era de sessenta passos e pode quase com facilidade levantar um elefante ou qualquer animal grande. Causa grandes prejuízos aos habitantes e seu vôo é muito rápido. ${ }^{11}$

O roc é um pássaro fabuloso que está presente na obra clássica de origem árabe Mil e uma noites. Porém, quinhentos anos antes da data da obra de Fra Mauro, um cronista árabe em um escrito sobre Sofala se refere a uma história análoga. Nela um bote não somente arrastou a tripulação a uma tempestade, mas também encontrou o roc.

\footnotetext{
${ }^{9}$ Apud CRONE, op. cit., p. 61.

${ }^{10}$ DORÉ, Andréa. Cristãos na Índia no século XVI: a presença portuguesa e os viajantes italianos. Revista Brasileira de História, vol. 22, nº44, 2002, p. 313.

${ }^{11}$ Apud CRONE, op. cit., p. 69.
} 
Desta forma, o veneziano construiu seu mapa apoiando-se também em fontes árabes, que se apropriam dessa tradição lendária.

Comparando-se os dois trechos presentes no mapa de Fra Mauro observa-se sua contradição. No primeiro há a afirmação da utilização apenas de informações comprovadas pela experiência, mas, no segundo têm-se os dados referentes a lendas árabes. Ou seja, a experiência provinda com as navegações portuguesas por um lado não significa necessariamente que a tradição seria banida do mapa. Pois o próprio Fra Mauro não era capaz de perceber a contradição existente.

Além disso, ao produzir um mapa nesse período, o uso das informações do cartógrafo dependia muito do seu contexto próprio. Ele selecionava os dados que estivessem de acordo com a finalidade específica de seu produto, como o caso do mapa de Diogo Ribeiro, onde ele buscou retratar todos os descobrimentos até aquele momento. Porém, sua obra destinava-se a confirmar as pretensões espanholas acerca das Molucas, local onde o Tratado de Tordesilhas não tinha um limite de comum acordo entre os reinos ibéricos. $\mathrm{O}$ mapa foi então uma ferramenta para legitimar a posse dos espanhóis, e desta forma, a experiência náutica que então mostrava que as ilhas estavam do lado português não foi levada em conta.

Assim, construir um mapa-múndi na época renascentista significava utilizar-se dos novos dados sobre regiões exploradas pelas navegações. Contudo, como eles não podiam preencher todos os espaços do mapa-múndi, havia territórios ainda sob o domínio da tradição. Entretanto, a utilização dessas informações ou da tradição ou da experiência foi permanentemente condicionada pelo contexto próprio do autor. 